\title{
Transient thermal Ansys analysis of dry contacts - Application to automotive braking
}

\author{
Ali Belhocine ${ }^{a}$ And Mostefa Bouchetara \\ Faculty of Mechanical Engineering, University of Sciences and Technology of Oran, BP 1505 El-Mnaouer, \\ USTO 31000 Oran, Algeria
}

Received 6 January 2011, Accepted 13 November 2011

\begin{abstract}
Braking operation is a process which converts the kinetic energy and the potential energy of the vehicle into other energies. The major part of the mechanical energy is transformed into heat. During the braking phase, the frictional heat generated at the interface disc-pads can lead to high temperatures. This phenomenon is even more important that the tangential stress as well as the relative sliding speeds in contact are important. The objective of this study is to analyse the thermal behavior of the full and ventilated brake discs of the vehicles using computing code ANSYS. The modeling of the temperature distribution in the disc brake is used to identify all the factors and the entering parameters concerned at the time of the braking operation such as the type of braking, the geometric design of the disc and the used material. The results obtained by the numerical simulation are satisfactory compared with those of the specialized literature.
\end{abstract}

Key words: Dry contact / brake discs / heat flux / heat transfer coefficient

Résumé - L'opération de freinage est un processus qui convertit l'énergie cinétique et l'énergie potentielle d'une automobile en d'autres énergies. La majeure partie de l'énergie mécanique est transformée en chaleur. Pendant la phase de freinage, la chaleur de friction produite au niveau de l'interface disque-plaquettes peut engendrer de hautes températures. Ce phénomène est d'autant plus important que les contraintes tangentielles ainsi que les vitesses relatives de glissement au contact sont importantes. L'objectif de cette étude est d'analyser le comportement thermique des disques de frein plein et ventilés des véhicules à l'aide du code de calcul ANSYS. La modélisation de la distribution de la température dans le disque de frein permet d'identifier tous les facteurs et les paramètres entrant en jeu lors de l'opération de freinage tels que le type de freinage, la conception géométrique du disque et le matériau utilisé. Les résultats obtenus par la simulation numérique sont satisfaisants comparés à ceux de la littérature spécialisée.

Mots clés : Contact sec / disques de frein / flux de chaleur / coefficient de transfert thermique

\section{Introduction}

The modeling of the problems involved in the phenomena of transfers in general and of thermals in particular is of primary importance, on the one hand, for the phase study or design of a product, and on the other hand, for the follow-up of the product in phase of operation. Parallel to technological progress, the significant projections were born in the field of the transfers of heat and of mass, and sciences related to thermals in particular and this discipline have developed for a few decades at intervals raised in many sectors: nuclear power, space, aeronautical, automobile, petro chemistry, etc. [1].

\footnotetext{
${ }^{a}$ Corresponding author: belhocine55@yahoo.fr
}

In 2002, Nakatsuji et al. [2] did a study on the initiation of hair-like cracks which formed around small holes in the flange of one-piece discs during overloading conditions. The study showed that thermally induced cyclic stress strongly affects the crack initiation in the brake discs. In order to show the crack initiation mechanism, the temperature distribution at the flange had to be measured. Using the finite element method, the temperature distribution under overloading was analysed. 3D unsteady heat transfer analyses were conducted using ANSYS. A $1 / 8$ of the piece disc was divided into finite elements, and the model had a half thickness due to symmetry in the thickness direction.

In 2000, Valvano \& Lee [3] did a study on the technique to determine the thermal distortion of a brake rotor. 


\section{Nomenclature}

\begin{tabular}{|c|c|}
\hline$a$ & Deceleration of the vehicle $\left(\mathrm{m} . \mathrm{s}^{-2}\right)$ \\
\hline$A$ & Matrix \\
\hline$A_{\mathrm{d}}$ & Disc surface swept by a brake pad $\left(\mathrm{m}^{2}\right)$ \\
\hline$[C]$ & Thermal capacity matrix $\left(\mathrm{J} . \mathrm{K}^{-1}\right)$ \\
\hline$C_{\mathrm{p}}$ & Specific heat $\left(\mathrm{J} \cdot \mathrm{kg}^{-1} \cdot \mathrm{K}^{-1}\right)$ \\
\hline$C_{\mathrm{d}}$ & Specific heat of disc $\left(\mathrm{J} \cdot \mathrm{kg}^{-1} \cdot \mathrm{K}^{-1}\right)$ \\
\hline$C_{\mathrm{p}}$ & Specific heat of pads $\left(\mathrm{J} \cdot \mathrm{kg}^{-1} \cdot \mathrm{K}^{-1}\right)$ \\
\hline$d_{\mathrm{Hyd}}$ & Hydraulic diameter of a radial channel (m) \\
\hline$E$ & Young modulus (MPa) \\
\hline$g$ & Gravitational acceleration $\left(\mathrm{m} \cdot \mathrm{s}^{-2}\right)$ \\
\hline$h$ & Convective heat transfer coefficient $\left(\mathrm{W} \cdot \mathrm{m}^{-2} \cdot \mathrm{K}^{-1}\right)$ \\
\hline$k$ & Thermal conductivity $\left(\mathrm{W} \cdot \mathrm{m}^{-1} \cdot \mathrm{K}^{-1}\right)$ \\
\hline$k_{\mathrm{d}}$ & Thermal conductivity of the disc $\left(\mathrm{W} \cdot \mathrm{m}^{-1} \cdot \mathrm{K}^{-1}\right)$ \\
\hline$k_{\mathrm{p}}$ & Thermal conductivity of the pad $\left(\mathrm{W} \cdot \mathrm{m}^{-1} \cdot \mathrm{K}^{-1}\right)$ \\
\hline$[K]$ & Thermal conductivity matrix $\left(\mathrm{W} . \mathrm{K}^{-1}\right)$ \\
\hline$\{L\}$ & Vector operator \\
\hline$L$ & Length of a plate (m) \\
\hline$l$ & Characteristic length (m) \\
\hline$m$ & Mass of the vehicle (kg) \\
\hline $\bar{n}$ & Unit normal \\
\hline$q_{0}$ & Heat flux entering the disc (W) \\
\hline$Q$ & Heat quantity generated during the friction $(\mathrm{J})$ \\
\hline$Q^{*}$ & Heat flux specified on a surface (W) \\
\hline$S_{\mathrm{d}}$ & Disc surface $\left(\mathrm{m}^{2}\right)$ \\
\hline$S_{\mathrm{p}}$ & Pads surface $\left(\mathrm{m}^{2}\right)$ \\
\hline$S_{\tau}$ & Surface temperature $\left(\mathrm{m}^{2}\right)$ \\
\hline$S_{\mathrm{Q}}$ & Surface in heat flux $\left(\mathrm{m}^{2}\right)$ \\
\hline$S_{\mathrm{c}}$ & Surface in convection $\left(\mathrm{m}^{2}\right)$ \\
\hline$t$ & Time (s) \\
\hline$T$ & Temperature (K) \\
\hline$T^{*}$ & Temperature specified on a surface \\
\hline$T_{\text {air }}$ & Ambient air temperature $\left({ }^{\circ} \mathrm{C}\right)$ \\
\hline$T_{\text {disc }}$ & Disc brake surface temperature $\left({ }^{\circ} \mathrm{C}\right)$ \\
\hline$T_{\mathrm{f}}$ & Fluid temperature $(\mathrm{K})$ \\
\hline$T_{\mathrm{P}}$ & Temperature imposed (K) \\
\hline$u$ & Speed of an incidental vent $\left(\mathrm{m} . \mathrm{s}^{-1}\right)$ \\
\hline$V$ & Speed of flow $\left(\mathrm{m} . \mathrm{s}^{-1}\right)$ \\
\hline$\nu$ & Initial speed of the vehicle $\left(\mathrm{m} . \mathrm{s}^{-1}\right)$ \\
\hline$\{\nu\}$ & Vector speed of mass transport \\
\hline & Braking effectiveness \\
\hline
\end{tabular}

The severe thermal distortion of a brake rotor can affect important brake system characteristics such as the system response and brake judder propensity. As such, the accurate prediction of thermal distortions can help in the designing of a brake disc.

In 1997, Hudson \& Ruhl [4] did a study on the air flow through the passage of a Chrysler LH platform ventilated brake rotor. Modifications to the production rotor's vent inlet geometry are prototyped and measured in addition to the production rotor. Vent passage air flow is compared to existing correlations. With the aid of Chrysler Corporation, investigation of ventilated brake rotor vane air flow is undertaken. The goal was to measure current vane air flow and to improve this vane flow to increase brake disc cooling.

The knowledge of the temperatures of contact is an invaluable element for the study of the tribological behavior

\begin{tabular}{|c|c|}
\hline \multicolumn{2}{|r|}{ Greek symbols } \\
\hline$\alpha$ & Thermal expansion coefficient $\left(1{ }^{\circ} \mathrm{C}\right)$ \\
\hline$\beta$ & Dilation coefficient of the air $\left(1^{\circ} \mathrm{C}\right)$ \\
\hline$\varepsilon_{\mathrm{p}}$ & Factor load distribution on the disc surface \\
\hline$\nu$ & Poisson coefficient \\
\hline$\rho$ & Mass density $\left(\mathrm{kg} \cdot \mathrm{m}^{-3}\right)$ \\
\hline$\rho_{\mathrm{d}}$ & Mass density of disc $\left(\mathrm{kg} \cdot \mathrm{m}^{-3}\right)$ \\
\hline$\rho_{\mathrm{p}}$ & Mass density of pads $\left(\mathrm{kg} \cdot \mathrm{m}^{-3}\right)$ \\
\hline$\nu$ & Kinematic viscosity $\left(\mathrm{m}^{2} \cdot \mathrm{s}^{-1}\right)$ \\
\hline$\varphi_{\mathrm{c}}$ & Heat partitioning factor \\
\hline$\varphi_{\mathrm{d}}$ & Heat quantity assumed by the $\operatorname{disc}(\mathrm{J})$ \\
\hline$\varphi_{\mathrm{p}}$ & Heat quantity assumed by the pad $(\mathrm{J})$ \\
\hline$\phi$ & $\begin{array}{l}\text { Rate distribution of the braking forces } \\
\text { between the front and rear axle }\end{array}$ \\
\hline$\omega$ & Angular velocity (rad.s $\left.{ }^{-1}\right)$ \\
\hline \multicolumn{2}{|r|}{ Adimensional numbers } \\
\hline$G r$ & Grashof number (-) \\
\hline$N u$ & Nusselt number (-) \\
\hline $\operatorname{Pr}$ & Prandtl number $(-)$ \\
\hline$R e$ & Reynolds number (-) \\
\hline$R e_{\omega}$ & Reynolds number in rotation $(-)$ \\
\hline \multicolumn{2}{|r|}{ Index } \\
\hline FG & Grey cast iron \\
\hline CFD & Computational fluid dynamic \\
\hline
\end{tabular}

of materials in slipping contact. Indeed, the mechanical power transmitted to a rubbing contact is primarily dissipated in the form of heat on the level of the interface of two materials. Rise resulting from the temperature can strongly influence the properties of surface of materials in slip, support physicochemical and microstructural transformations and modify the rheology of the interfacial elements present in the contact [5].

Recent numerical models, presented to deal with rolling processes $[6,7]$ have shown that the thermal gradients can attain important levels which depend on the heat dissipated by friction, the rolling speed and the heat convection coefficient. Many other works [8,9] dealt with the evaluation of temperature in solids subjected to frictional heating. The temperature distribution due to friction process necessitates a good knowledge of the contact parameters. In fact, the interface is always imperfect - due to the roughness - from a mechanical and thermal point of view. Recent theoretical and experimental works [10,11] have been developed to characterise the thermal parameters which govern the heat transfer at the vicinity of a sliding interface. In certain industrial applications, the solids are provided with surface coating. A recent study has been carried out to analyse the effect of surface coating on the thermal behaviour of a solid subjected to friction process $[12]$.

The thermal analysis is a primordial stage in the study of the brake systems, because the temperature determines thermomechanical behavior of the structure. In the braking phase, temperatures and thermal gradients are very high. This generates stresses and deformations whose consequences are manifested by the appearance and the accentuation of cracks $[13,14]$. It is then important to determine with precision the temperature field of the brake 
disc. During the stop braking, the temperature does not have time to be stabilized in the disc. A transient analysis is required. It is also essential to evaluate the thermal gradients, what requires a three-dimensional modeling of the problem. The thermal loading is represented by a heat flux entering the disc through the brake pads.

The numerical simulation in fluid and thermal mechanics is currently in full expansion in industry, in particular in the automobile area.

In this study, we will present a numerical modeling in three dimensions to analyse the thermal behavior of the full and ventilated disc brake. This solution is applied to the problem of determining the transient temperatures reached at the friction surfaces of a disk brake when a constant deceleration is produced during braking [15].

The modeling will be carried out in transient state, simulating a stop braking of which the rotational speed of the disc and the flux generated by friction are functions of time.

The thermal calculation based on the finite element method will be carried out using code ANSYS 11. This last is elaborated out for the resolution of complex physical systems.

In the case of disc brake, the effective friction processes between the pads and the disc are extremely complex due to the fact that the present time brake pads, due to their composite structure [16], do not have constant chemicalphysic properties, the organic contained elements being subject of a series of transformations under the influence of temperature increase. The heat distribution between the brake disc and the friction pads is mostly dependent on material characteristics, among whom a major influence is due to the density $\rho_{\mathrm{d}, \mathrm{p}}\left[\mathrm{kg} \cdot \mathrm{m}^{-3}\right]$, the thermal conductivity $k_{\mathrm{d}, \mathrm{p}}\left[\mathrm{W} \cdot \mathrm{m}^{-1} . \mathrm{K}\right]$ and the specific heat $C_{\mathrm{d}, \mathrm{p}}\left[\mathrm{J}_{\mathrm{kg}} \mathrm{kg}^{-1} \mathrm{~K}\right]$ of discs (index d) and braking pad's materials respectively (index $\mathrm{p}$ ). Denoting $Q_{\mathrm{d}}$ and $Q_{\mathrm{g}}[\mathrm{J}]$ the heat quantities assumed by the disc and the braking pads respectively, one could be expressed in the following manner [17]

$$
\frac{Q_{\mathrm{d}}}{Q_{\mathrm{p}}}=\frac{\sqrt{\rho_{\mathrm{d}} k_{\mathrm{d}} C_{\mathrm{d}}}}{\sqrt{\rho_{\mathrm{p}} k_{\mathrm{p}} C_{\mathrm{p}}}}
$$

Because the braking disc is not entirely covered by the friction pads, within computing we have to consider the ratio between the disc surface $S_{\mathrm{d}}$ and the pads surface $S_{\mathrm{p}}$. Denoting the ratio of heat's division, between the disk and pads with

$$
\varphi_{\mathrm{c}}=\frac{Q_{\mathrm{d}}}{Q_{\mathrm{p}}} \frac{S_{\mathrm{d}}}{S_{\mathrm{p}}}=\frac{\sqrt{\rho_{\mathrm{d}} k_{\mathrm{d}} C_{\mathrm{d}}}}{\sqrt{\rho_{\mathrm{p}} k_{\mathrm{p}} C_{\mathrm{p}}}}, \frac{S_{\mathrm{d}}}{S_{\mathrm{p}}}
$$

and considering $Q[\mathrm{~J}]$ the heat quantity generated during the friction process, the heat quantities assumed by the pads and by the disc are:

$$
\begin{aligned}
& \varphi_{\mathrm{d}}=Q \frac{\varphi_{\mathrm{c}}}{1+\varphi_{\mathrm{c}}} \\
& \varphi_{\mathrm{g}}=Q \frac{1}{1+\varphi_{\mathrm{c}}}
\end{aligned}
$$

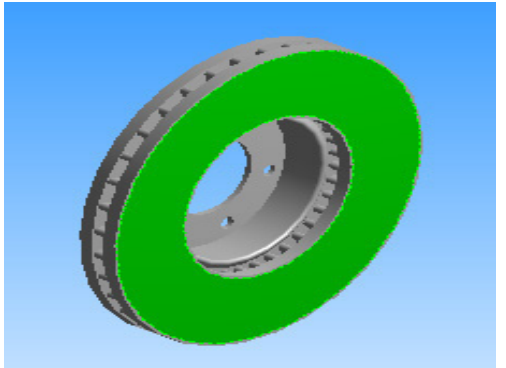

Fig. 1. Application of flux.

The brake disk assumes the most part of the heat, usually more than $90 \%$ [18], through the effective contact surface of the friction coupling. Considering the complexity of the problem and average data processing limited, one replaced the pads by their effect, represented by an entering heat flux (Fig. 1).

\section{Heat flux entering the disc}

In a braking system, the mechanical energy is transformed into a calorific energy. This energy is characterized by a total heating of the disc and pads during the braking phase. The energy dissipated in the form of heat can generate rises in temperature ranging from $300{ }^{\circ} \mathrm{C}$ to $800{ }^{\circ} \mathrm{C}$. The heat quantity in the contact area is the result of plastic micro-deformations generated by the friction forces.

Generally, the thermal conductivity of material of the brake pads is smaller than of the disc $\left(k_{\mathrm{p}}<k_{\mathrm{d}}\right)$. We consider that the heat quantity produced will be completely absorbed by the brake disc. The heat flux evacuated of this surface is equal to the power friction. The initial heat flux $q_{0}$ entering the disc is calculated by the following formula [19]:

$$
q_{0}=\frac{1-\phi}{2} \cdot \frac{m g \nu z}{2 A_{\mathrm{d}} E_{\mathrm{p}}}
$$

where

$z=a / g$ : braking effectiveness

$a$ : deceleration of the vehicle $\left[\mathrm{m} . \mathrm{s}^{-2}\right]$

$\varphi$ : rate distribution of the braking forces between the front and rear axle

$A_{\mathrm{d}}$ : disc surface swept by a brake pad $\left[\mathrm{m}^{2}\right]$

$V$ : initial speed of the vehicle $\left[\mathrm{m} . \mathrm{s}^{-1}\right]$

$\varepsilon_{\mathrm{p}}$ : factor load distribution on the surface of the disc

$M$ : mass of the vehicle $[\mathrm{kg}]$

Figure 2 shows the ventilated disc-pads and the applied forces.

The loading corresponds to the heat flux on the disc surface. The dimensions and the parameters used in the thermal calculation are recapitulated in Table 1.

The disc material is gray cast iron with high carbon content FG, with good thermophysical characteristics those are given in Table 2. The thermal conductivity and specific heat are a function of temperature [20], Figures 3 and 4 . 


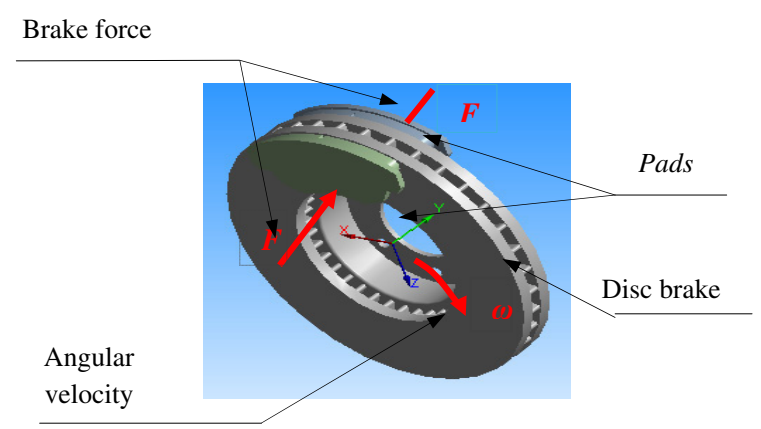

Fig. 2. Disc-pads assembly with forces applied to the disc.

Table 1. Geometrical dimensions and application parameters of automotive braking.

\begin{tabular}{cc}
\hline Inner disc diameter $(\mathrm{mm})$ & 66 \\
Outer disc diameter $(\mathrm{mm})$ & 262 \\
Disc thickness $(\mathrm{mm})$ & 29 \\
Disc height $(\mathrm{mm})$ & 51 \\
Vehicule mass $-m(\mathrm{~kg})$ & 1385 \\
Initial speed $-v_{0}\left(\mathrm{~km} \cdot \mathrm{h}^{-1}\right)$ & 28 \\
Deceleration $-a\left(\mathrm{~m}^{-2}\right)$ & 8 \\
Effective rotor radius $-R_{\mathrm{rocor}}-(\mathrm{mm})$ & 100.5 \\
Rate distribution of the braking forces $-\phi-(\%)$ & 20 \\
Factor of charge distribution on the disc $\varepsilon_{\mathrm{p}}$ & 0.5 \\
Surface disc swept by the pad $A_{\mathrm{d}}\left(\mathrm{mm}^{2}\right)$ & 35993 \\
\hline
\end{tabular}

Table 2. Thermophysical properties of the disc.

\begin{tabular}{cc}
\hline Young modulus $E(\mathrm{MPa})$ & 138000 \\
Poisson coefficient $\nu$ & 0.28 \\
Density $\rho\left(\mathrm{kg} \cdot \mathrm{m}^{-3}\right)$ & 7250 \\
Thermal expansion $\alpha\left(1{ }^{\circ} \mathrm{C}\right)$ & $1.085 \times 10^{-5}$ \\
Tensile strength $(\mathrm{MPa})$ & 300 \\
Compressive strength $(\mathrm{MPa})$ & 820 \\
\hline
\end{tabular}

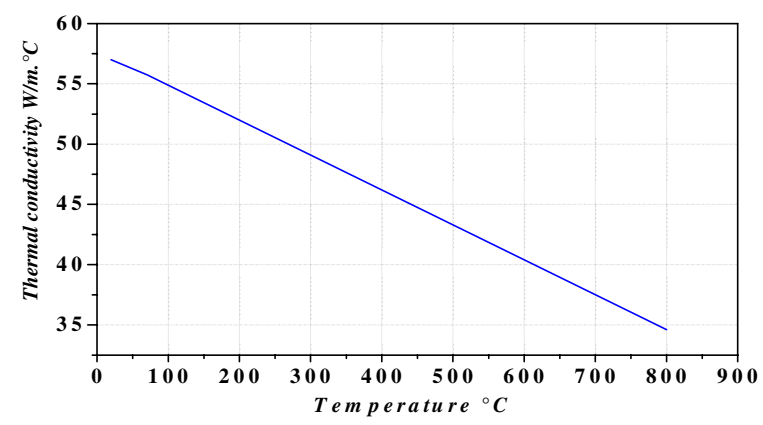

Fig. 3. Thermal conductivity as a function of temperature.

\section{Numerical modeling of the thermal problem}

\subsection{Equation of the problem}

The first law of thermodynamics indicating the thermal conservation of energy gives:

$$
\rho C_{\mathrm{p}}\left(\frac{\partial T}{\partial t}+\{\nu\}^{T}\{L\}\right)+\{L\} T\{Q\}=p
$$

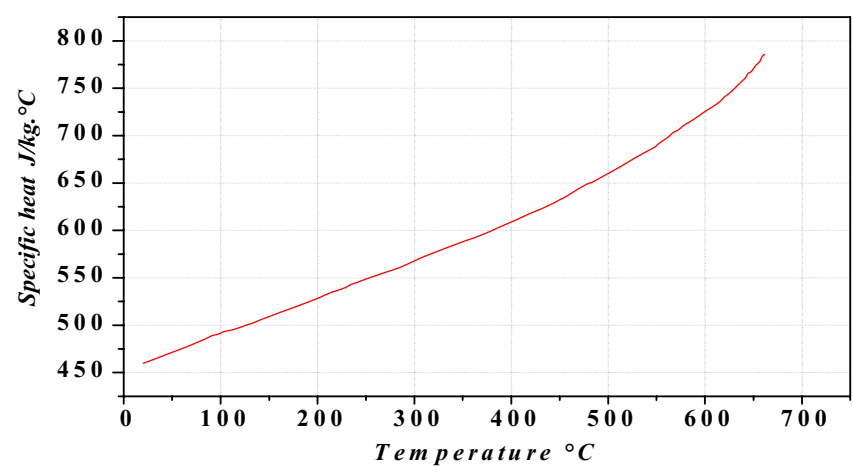

Fig. 4. Specific heat versus temperature.

In our case there is not an internal source $p=0$, thus Equation (6) is written:

$$
\rho C_{\mathrm{p}}\left(\frac{\partial T}{\partial t}+\{\nu\}^{T}\{L\}\right)+\{L\} T\{Q\}=0
$$

with :

$$
\begin{array}{r}
\{L\}=\left\{\begin{array}{c}
\frac{\partial}{\partial x} \\
\frac{\partial}{\partial y} \\
\frac{\partial}{\partial z}
\end{array}\right\} \\
\{\nu\}=\left\{\begin{array}{l}
\nu_{x} \\
\nu_{y} \\
\nu_{z}
\end{array}\right\}
\end{array}
$$

The law of Fourrier (7) can be written in the following matrix form:

$$
\{Q\}=-[K]\{L\} T
$$

with:

$$
[K]=\left[\begin{array}{ccc}
k_{x x} & 0 & 0 \\
0 & k_{y y} & 0 \\
0 & 0 & k_{z z}
\end{array}\right]
$$

$k_{x}, k_{y}$ and $k_{z}$ represent the conditions along axes $x, y$, $z$ respectively. In our case the material is isotropic thus $k_{x x}=k_{y y}=k_{z z}$ :

- $\{L\}$ Vector operator.

$-\{\nu\}$ Vector speed of mass transport.

- $[K]$ Matrix conductivity.

By combining two Equations (7) and (10), we obtain:

$$
C_{\mathrm{p}}\left(\frac{\partial T}{\partial t}+\{\nu\}^{T}\{L\} T\right)=\{L\}^{T}([K]\{L\} T)
$$

By developing Equation (12) one deduces:

$$
\begin{aligned}
& \rho C_{\mathrm{p}}\left(\frac{\partial T}{\partial t}+\nu_{x} \frac{\partial T}{\partial x}+\nu_{y} \frac{\partial T}{\partial y}+\nu_{z} \frac{\partial T}{\partial z}\right) \\
& =\frac{\partial}{\partial x}\left(K_{x} \frac{\partial T}{\partial x}\right)+\frac{\partial}{\partial y}\left(K_{y} \frac{\partial T}{\partial y}\right)+\frac{\partial}{\partial z}\left(K_{z} \frac{\partial T}{\partial z}\right)
\end{aligned}
$$




\subsection{Initial conditions}

According to experimental tests evoked in the literature, in our study, one considers that the initial temperature is equal to:

$$
T(x, y, z)=60{ }^{\circ} \mathrm{C} \quad \text { at time } \quad t=0
$$

\subsection{Boundary conditions}

In general, in a thermal study, one finds three types of boundary conditions:

1. Temperature specified on a surface

$$
S_{\mathrm{T}}: T=T^{*}
$$

2. Heat flux specified on a surface

$$
S_{Q}:\{Q\}^{T}\{n\}=Q^{*}
$$

3. Convection specified on a surface

$$
S_{\mathrm{c}}:\{Q\}^{T}\{n\}=h\left(T_{\mathrm{p}}-T_{\mathrm{f}}\right)
$$

In the case of a disc of brake in rotation we are in presence of a forced convection. In this case the convection can be represented according to the following variables:

$$
F(R e, R r, N u)=0
$$

where $R e$ is the Reynolds number $=V l / \nu, N u$ is the Nusselt number $=h l / k$ and $P r$ is the Prandtl number $=$ $\nu \rho C_{\mathrm{p}} / k$.

One solves thus the function $F$ compared to the heat transfer coefficient $h$, or better, compared to the Nusselt number to have an expression without dimension

$$
N u=f(R e, P r)
$$

Often an approach of the type

$$
N u=C \cdot \operatorname{Re}^{m} \operatorname{Pr}^{m}
$$

is used for the correler with the tests results.

Convection on various surfaces of the brake disc differ according to its geometry and its exposure. In Figure 5, various surfaces of a section disc and their classification are shown as follows.

\section{(a) Surfaces of types A}

Dennis and Morgan [22] establish an empirical equation for the calculation of the Nusselt number for brake discs in rotation and exposed to an incidental wind

$$
N u=0.0436\left(\frac{R e}{R e_{\omega}}\right)^{0.74} R e_{\omega}^{0.9}
$$

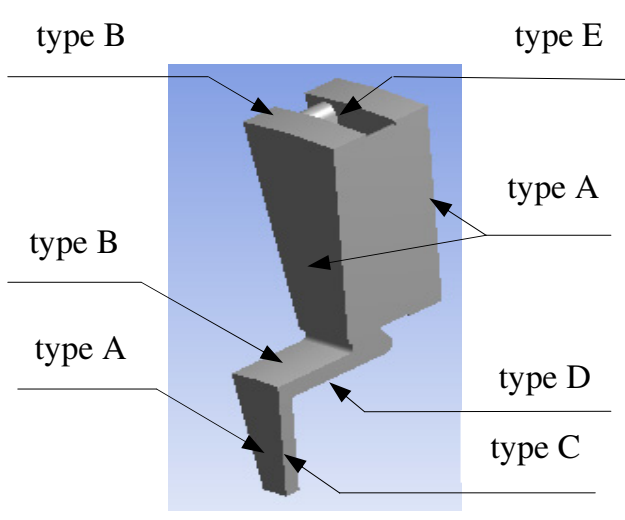

Fig. 5. Various surfaces of a section disc.

\section{(b) Surfaces of types B}

Kays \& Bjorklund [23] establish the empirical Equation (22) for the Nusselt number of external cylindrical surfaces

$$
N u=0.135\left(\left(0.5 R e_{\omega}^{2}+R e^{2}+G r\right) P r\right)^{\frac{1}{3}}
$$

where $G r$ is the Grashof number $=\frac{\beta g d_{\mathrm{dis}}^{3}\left(T_{\mathrm{disc}}-\tau_{\mathrm{air}}\right)}{\nu^{2}}$.

\section{(c) Surfaces of types C}

In the case of a laminar boundary layer [24,25]

$$
R e_{\omega, \text { crit }}<240000 \ldots 300000
$$

one adopts the equation of Cobb and Saunders [24]

$$
N u=C \sqrt{R e_{\omega}}
$$

Several authors recommend values differences for constant $C$ according to the correlation with measurements (Tab. 3). One supposes that the temperature of the friction tracks does not vary with the ray.

\section{(d) Surfaces of types D}

For this type of surface, one adopts a proposal of Schwarz et al. [28]. This proposal is based on the assumption that heat surface flux of surfaces of the type $D$ is the same one as in a drum in rotation.

An empirical equation of Mc Adams [29] is adopted.

$$
N u=0.14\left(\frac{L^{3} g \beta\left(T_{\text {disc }}-T_{\text {air }}\right) P r}{\nu^{2}}\right)^{\frac{1}{3}}
$$

\section{(e) Surfaces of types E}

In the case of a laminar flow [21-30]:

$$
R e<2320
$$


Table 3. Values of constant C.

\begin{tabular}{ll}
\hline Authors & Values of C \\
Dorfman [26] & 0.399 \\
Millsaps, Pohlhausen [26] & $0.322(\operatorname{Pr}=0.72)$ \\
Fukano [27] & $0.399 \operatorname{Pr} r^{0.43}$ \\
Cobb, Saunders [26] & $0.36(\operatorname{Pr}=0.72)$ \\
\hline
\end{tabular}

One adopts an equation of Ehlers [25] based on an approach of Elser [25], multiplied by a factor of 1.7

$$
N u=0.983 \frac{\sqrt{V} \operatorname{Pr}^{\frac{3}{3}} d_{\mathrm{Hyd}}}{\sqrt{\nu l}}
$$

\section{Determination of the coefficient of exchange by convection $(h)$}

\subsection{Introduction}

The thermal analysis of the braking system requires a precise determination of the quantity of heat friction produced and as well as the distribution of this energy between the disc and the brake lining. During an emergency braking, all the heat produced with the interface is equal to the heat absorbed by the disc and the brake lining [31].

When a vehicle is braked, a part of the frictional heat escapes in the air ambient by convection and radiation. Consequently, the determination of the heat transfer coefficients is essential. Their exact calculation is however rather difficult, because these coefficients depend on the location and the construction of the braking system, the speed of the vehicle travel and consequently of the air circulation. Since the process of heat transfer by radiation is not too important, we will determine using code ANSYS CFX only the convection coefficient $(h)$ of the disc. This parameter will be exploited to determine the threedimensional distribution of the temperature of the disc.

\subsection{Modeling in ANSYS CFX}

The first stage is to create the model CFD which contains the fields to be studied in Ansys Workbench. In our case, we took only one quarter of the disc, then we defined the field of the air surrounding this disc. ANSYS ICEM CFD will prepare various surfaces for the two fields in order to facilitate the mesh on which that one will export the results towards CFX using the command "Output to cfx" [32]. After obtaining the model on CFX Pre and specified the boundary conditions, we must define these physical values come into play on CFX to start calculation.

The disc is related to four adiabatic surfaces and two surfaces of symmetry in the fluid domain whose ambient temperature of the air is taken equal at $20{ }^{\circ} \mathrm{C}$ and open boundaries with zero relative pressure were used for the

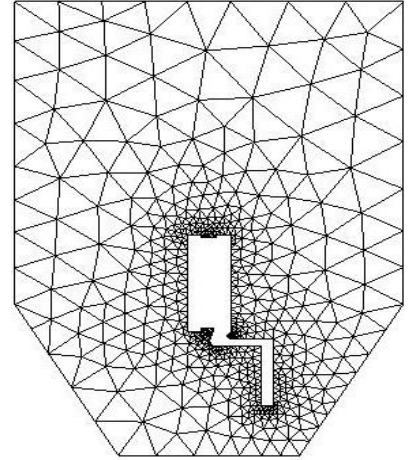

Fig. 6. Irregular mesh in the wall.

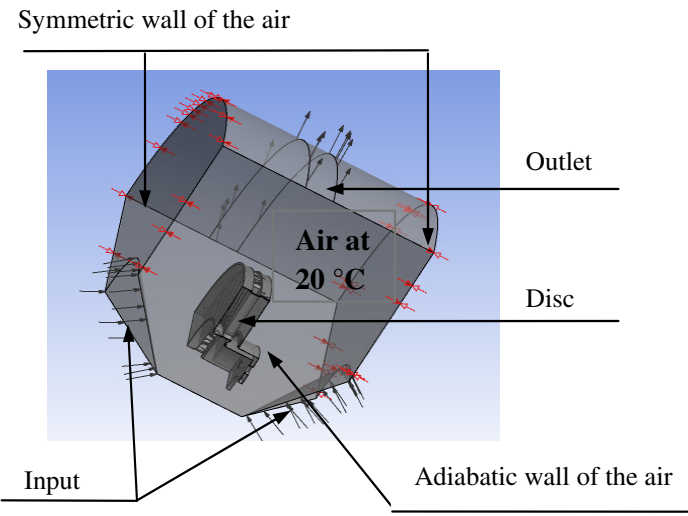

Fig. 7. Brake disc CFD model.

upper, lower and radial ends of the domain [33]. For the considered cases, disc rotational Reynolds $\left(R e_{\omega}\right)$ numbers are larger than $2.5 \times 10^{5}$, and the flow is turbulent. The solution scheme employs the $\kappa-\varepsilon$ model with scalable wall function and sequential load steps. For the preparation of the mesh of CFD model, we used a linear tetrahedral element with 30717 nodes and 179798 elements. In order not to weigh down calculation, an irregular mesh is used in which the meshs are broader where the gradients are weaker (not-uniform mesh) (Fig. 6).

Figure 7 shows the elaborate model CFD which will be used in ANSYS CFX Pre.

\section{(a) Physical model}

In this step, one declares all of the physical characteristics of the fluid and the solid. After the meshing, are defined all the parameters of the different models to be able to start the analysis.

\section{(b) Definition of the domains}

Initially, one validates the elaborated models and one activates in the option "Thermal Energy" the calculation of heat transfer "Heat Transfer".

Fluid domain: speed entry: $V_{\text {ent non.st }}=V_{\text {ent }}-\mathrm{Va} \cdot \mathrm{t}$. 
Disc domain: entering flux: FLUX $_{\text {non.st }}=(C F)$ $\left(V_{\text {ent non.st }}\right), C F=149893.838$.

$V_{\text {ent non.st }}=V_{\text {ent }}-$ Vat $t$

FLOW ${ }_{\text {non.st }}$ : non stationary flux entering.

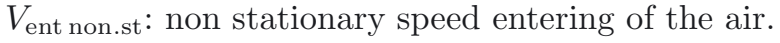

\section{(c) Definition of materials}

We introduce into the library the physical properties of used materials. In this study we selected three cast iron materials (FG $25 \mathrm{Al}, \mathrm{FG} 20$ and FG 15).

\section{(d) Definition of the boundary conditions}

The first step is to select the Inlet and Outlet faces of the heat flux. These options are found in the insertion menu "Boundary Conditions" in the CFX Pre.

The boundary conditions concerning the pads will be also defined. One selects the options "Wall" and "Symmetry", because there will be the possibility of adjusting a certain number of parameters in the boundary conditions such as flux entering the disc.

\section{(e) Application of the interfaces domains}

The areas of interfaces are commonly used to create the connection or linkage areas. Surfaces located between the interactions regions (air-disk) are reported as solidfluid interface.

\section{(f) Temporary condition}

Since in this study is to determine the temperature field in a disc brake during the braking phase of a vehicle of average class, we take the following temporal conditions:

- Braking time $=3.5[\mathrm{~s}]$.

- Increment time $=0.01[\mathrm{~s}]$.

- Initial time $=0[\mathrm{~s}]$.

Before starting the calculation and the analysis with ANSYS CFX PRE, it is ensured that the model does not contain any error.

\section{(g) Launch of the calculation}

After verification of the model and boundary conditions, we run the calculation by opening the menu "File" and clicking on "Write solver file". The values of the coefficient of exchange will be taken average values calculated by the minimal and maximum values obtained using ANSYS CFX POST as it east indicates in the Figure 8.

Figure 9 shows CFD results of the distribution of the velocity on the surfaces of the vanes and channels in the ventilated commercial vehicle brake disc. It is noted that speed has a fall value at the exit of the vanes of the disc.

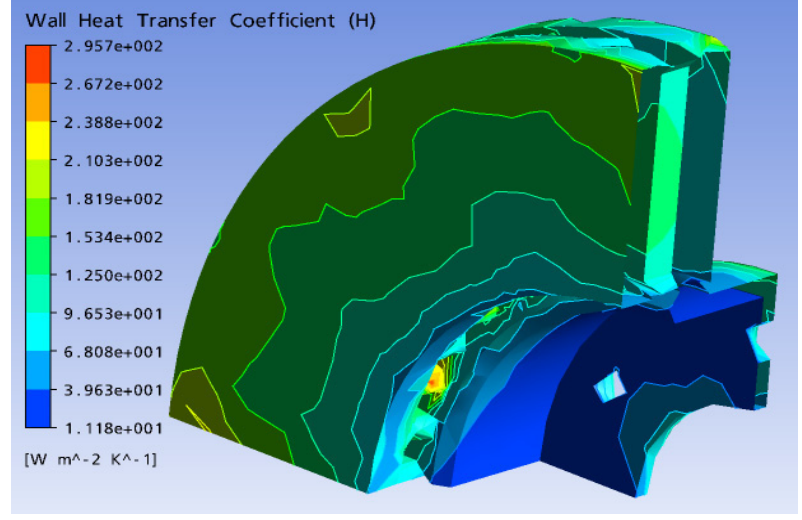

Fig. 8. Distribution of heat transfer coefficient on a ventilated disc in the stationary case (FG 15).

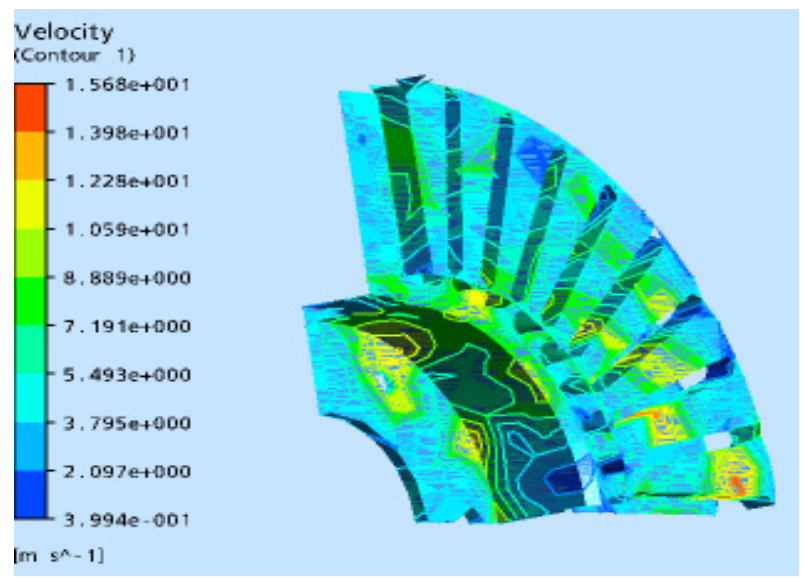

Fig. 9. Velocity distribution inside the ventilated disc.

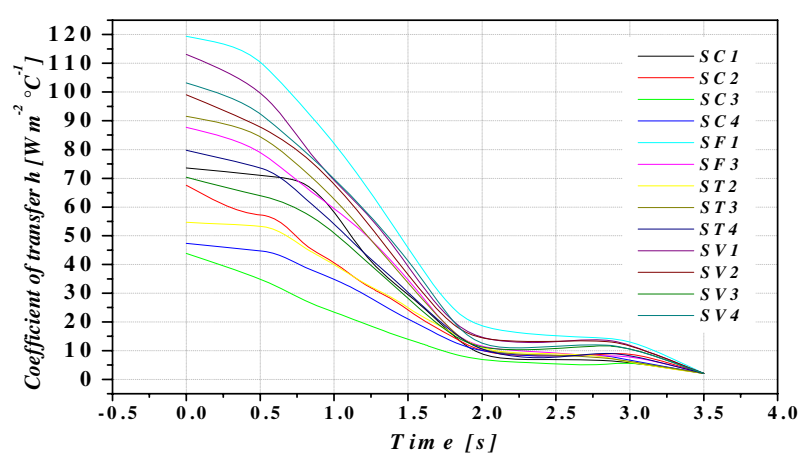

Fig. 10. Variation of heat transfer coefficient $(h)$ of various surfaces for a full disc in the non stationary case (FG 15).

\section{(h) Results of the calculation of the coefficient $h$}

Figures 10 and 11 show the variation of the heat transfer coefficient $(h)$ of different surfaces respectively for a full and ventilated disc in cast iron (FG 15) in transient state. We found that after a short time all the curves of $h$ are decreasing with time.

The computation results of digital enables us to obtain the graphs of a Nusselt number according to the Reynolds number in rotation (Fig. 12). 


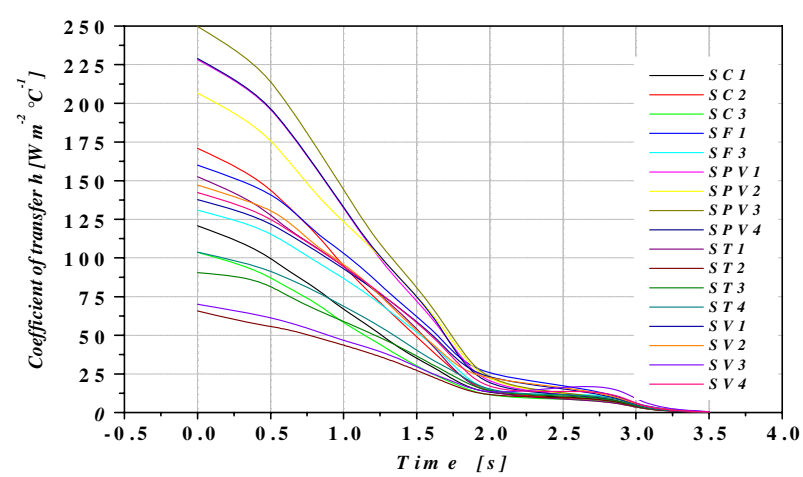

Fig. 11. Variation of heat transfer coefficient $(h)$ of various surfaces for a ventilated disc in transient case (FG 15).

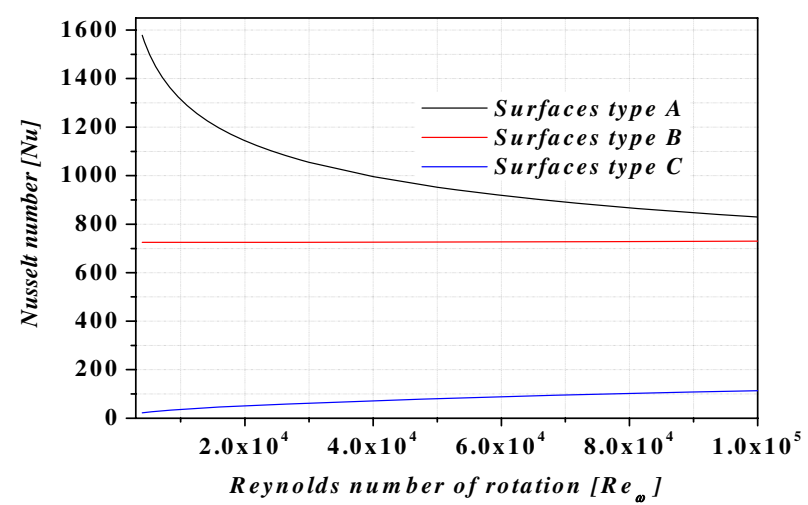

Fig. 12. Nusselt number according to the Reynolds number rotational.

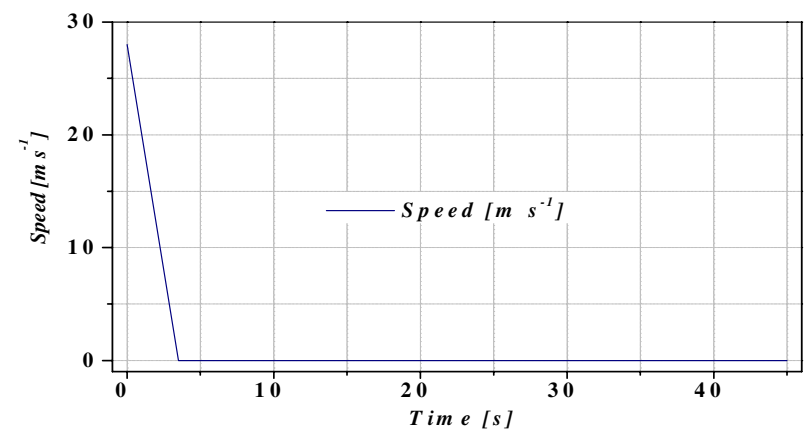

Fig. 13. Speed of braking versus time (braking of type 0).

\section{Determination of the disc temperature}

The modeling of the disc temperature is carried out by simulating a stop braking of a middle class car (braking of type 0 ).

The characteristics of the vehicle and of the disc brake are listed in Table 1.

The vehicle speed decreases linearly with time until the value 0 as shown in Figure 13. The variation of the heat flux during the simulation time is represented in the Figure 14.

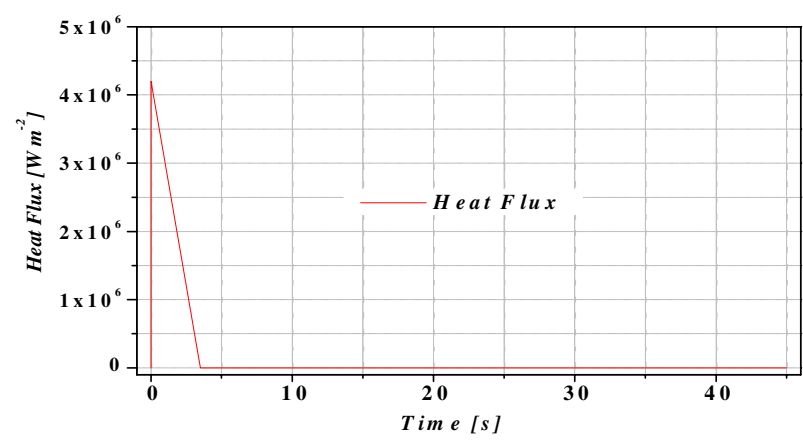

Fig. 14. Heat flux versus time.

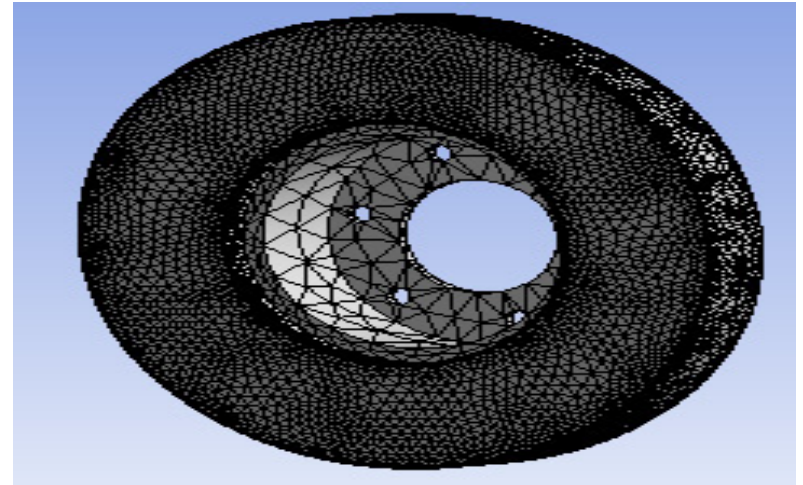

Fig. 15. Meshing of a full disc in ANSYS Multiphysics (172 103 nodes - 114421 elements).

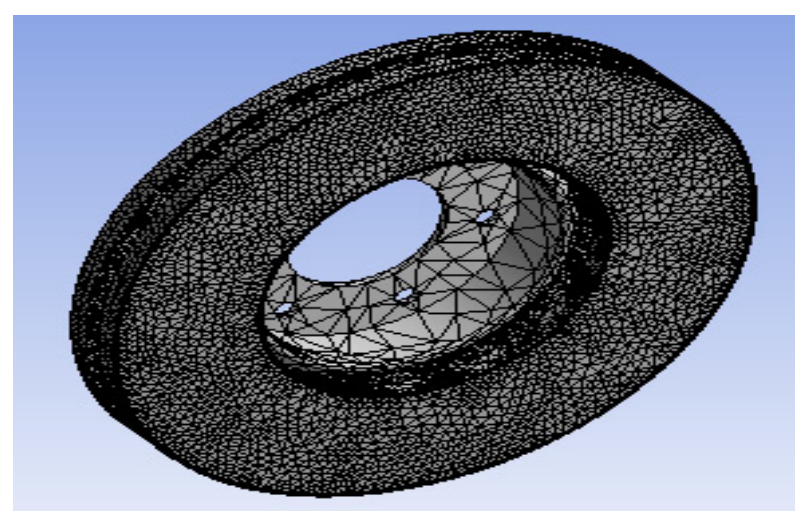

Fig. 16. Meshing of a ventilated disc in ANSYS Multiphysics (154679 nodes - 94117 elements).

\subsection{Meshing of the disc}

The heat gradients are very high, in the thickness of the disc, on the tracks of friction, in the throat of the bowl. One expects gradients of constraints raised in these same zones. The mesh must thus be fine enough for evaluating the gradients well. That increases the number by degrees of freedom of the model finite elements.

The elements used for the meshing of the full and ventilated disc are tetrahedral three-dimensional elements with 10 nodes (isoparametric) (Figs. 15 and 16). In this simulation, the meshing was refined in the contact zone 
Table 4. Number of elements of the two considered meshs.

\begin{tabular}{lcc}
\hline & Full disc & Ventilated disc \\
\hline & Number of elements & Number of elements \\
\hline Mesh 1 & 46025 & 77891 \\
Mesh 2 & 114421 & 94117 \\
Mesh 3 & 256613 & 369777 \\
\hline
\end{tabular}

(disc-pad). This is important because in this zone the temperature varies significantly.

Three meshes have been tested automatically using an option called convergence in ANSYS Workbench Multiphysics. The number of elements forming each meshing is given in Table 4.

\subsection{Loading and boundary conditions}

The thermal loading is characterized by the heat flux entering the disc through the real contact area (two sides of the disc). The initial and boundary conditions are introduced into module ANSYS Workbench. The thermal calculation will be carried out by choosing the transient state and by introducing physical properties of the materials. The selected data for the numerical application are summarized as follows:

- Total time of simulation $=45[\mathrm{~s}]$.

- Increment of initial time $=0.25[\mathrm{~s}]$.

- Increment of minimal initial time $=0.125[\mathrm{~s}]$.

- Increment of maximal initial time $=0.5[\mathrm{~s}]$.

- Initial temperature of the disc $=60\left[{ }^{\circ} \mathrm{C}\right]$.

- Materials: three types of cast iron (FG 25 AL, FG 20, FG 15).

\section{Results and discussions}

The modeling of temperature in the disc brake will be carried out by taking account of the variation of a certain number of parameters such as the type of braking, the cooling mode of the disc and the choice of disc material. The brake discs are made of cast iron with high carbon content; the contact surface of the disc receives an entering heat flux calculated by the relation (5).

Figure 17 shows the internal geometry of the ventilated disc.

\subsection{Influence of construction of the disc}

In the braking operation, the vehicle down from the maximum speed of $100.8 \mathrm{~km} \cdot \mathrm{h}^{-1}$ to a standstill (Fig. 18). The initial temperature of the disc and the surrounding is $60{ }^{\circ} \mathrm{C}$.

Figure 19 shows the variation of the temperature versus time during the total time simulation of braking for a full disc and a ventilated disc. The highest temperatures are reached at the contact surface disc-pads. The strong rise in temperature is due to the short duration

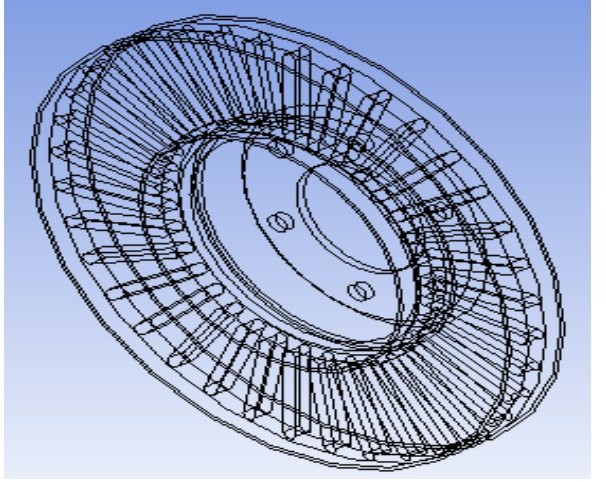

Fig. 17. Internal geometry of the ventilated disc.

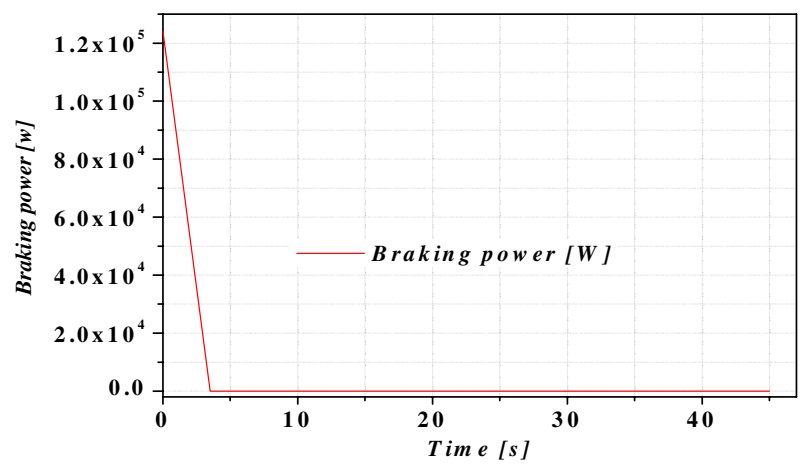

Fig. 18. Braking power dissipated by friction versus time.

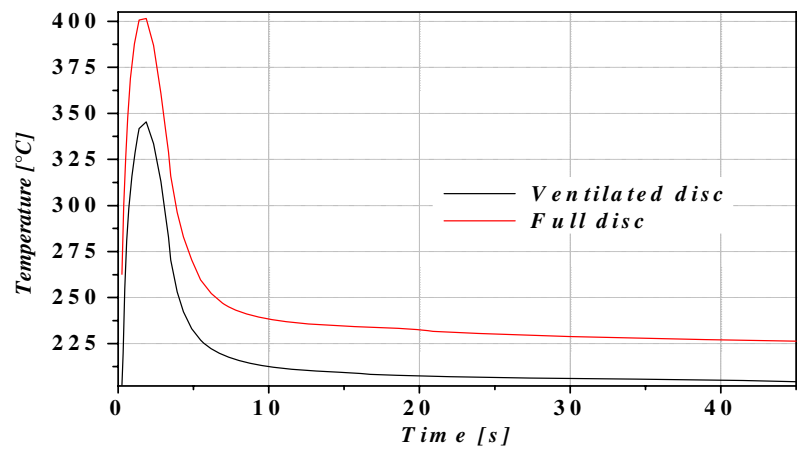

Fig. 19. Temperature variation of a full and ventilated disc (FG 15) versus time.

of the braking phase and to the speed of the physical phenomenon. For the two types of discs, one notices that starting from the first step of time one has a fast rise of the temperature of the disc followed by a fall of temperature after a certain time of braking.

We quickly notice that for a ventilated disc out of cast iron FG 15, the temperature increases until $T_{\max }=$ $345.44{ }^{\circ} \mathrm{C}$ at the moment $t=1.85 \mathrm{~s}$, then it decreases rapidly in the course of time. The variation in temperature between a full and ventilated disc having same material is about $60{ }^{\circ} \mathrm{C}$ at the moment $t=1.8839 \mathrm{~s}$ (Fig. 20). We can conclude that the geometric design of the disc is an essential factor in the improvement of the cooling process of the discs. 


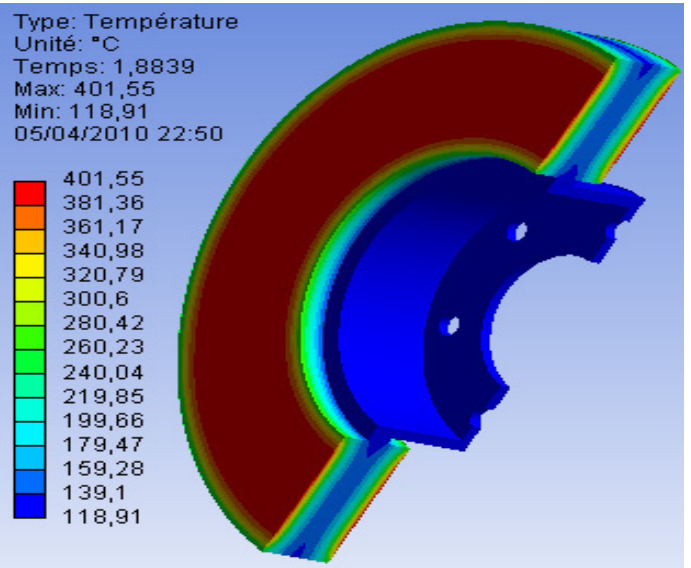

(a)

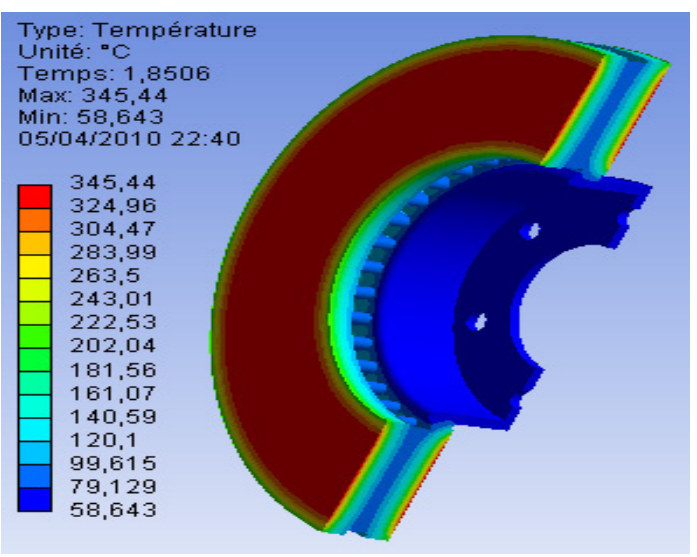

(b)

Fig. 20. Temperature distribution of a full (a) and ventilated disc (b) of cast iron (FG 15).

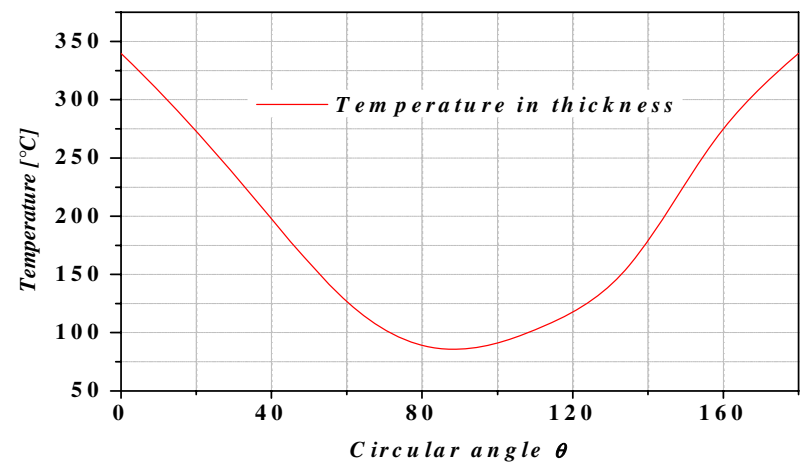

Fig. 21. Evolution of the disc temperature according to angular position at the thickness of a ventilated disc with cast iron (FG 15).

In Figure 21, disc temperature in angular direction is presented. It is noted that the profile of temperature is parabolic and symmetry is always noted when one takes the median plane vertical disc and the pace is the parabolic form has maximum values on the friction tracks of the disc.

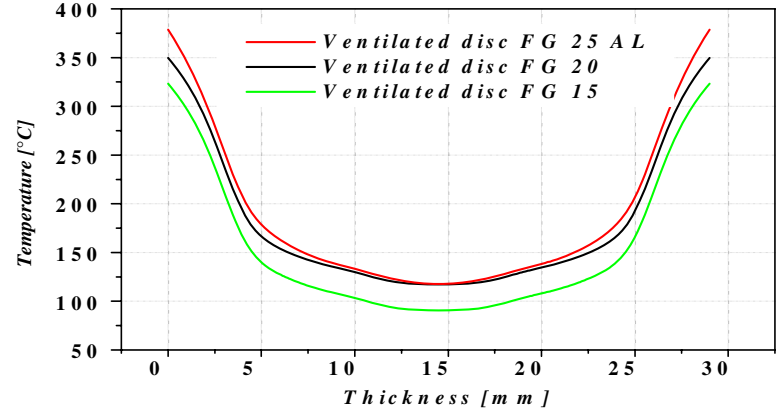

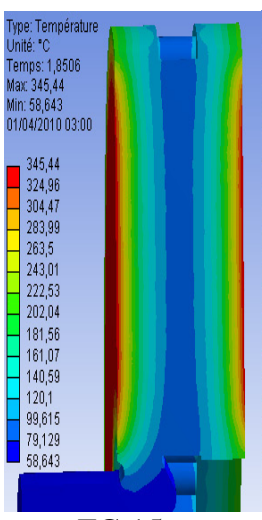

FG 15

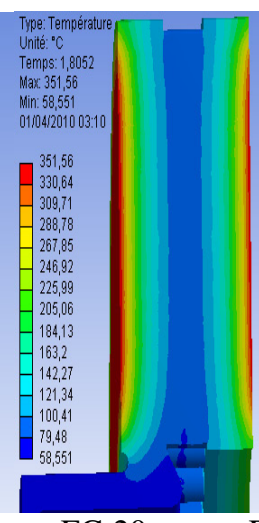

FG 20

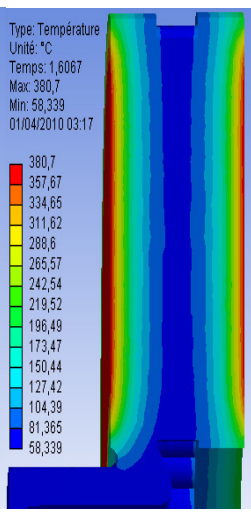

FG25 AL
Fig. 22. Temperature variation through a disc thickness for three types of cast irons (FG 25 AL, FG 20 and FG 15).

\subsection{Infuence of material of the disc}

Figure 22a shows for each type of the selected cast irons the temperature variation as a function of thickness at the moment when the temperature is maximum. The look of the three curves is similar. We also note that the temperature decreases in the direction of median plane of the disc to reach its minimal value. In Figure $22 \mathrm{~b}$ we see that there is inside the disc symmetry of colors. The part far away from the surface of blue contact color is not requested too much thermically. More the thermal conductivity of the material is low, more its temperature is high. The FG 15 is differentiated from the two other cast irons by smaller temperatures. The figure does not have symmetry because it is about a manual survey and not precise.

In Figure 23, the temperature variation versus radius for three materials (FG 25 Al, FG 20, FG 15) is presented. The shape of the temperature curves is the same one. The maximal temperature is in area of the mean disc radius.

According to Figures 22 and 23 the cast iron FG 15 has the best thermal behavior.

Figures 24 and 25 respectively show the temperature variation according to the thickness and radius. It is noted that there is an appreciable variation of temperature between the two types of full and ventilated disc. The peripheral fall of temperature of the graph 25 is explained by presence of the wings and the number of the vanes in the design of the ventilated disc which allows a good cooling state and storage capacity of energy decreases, (here the number of vanes is 36 ). 


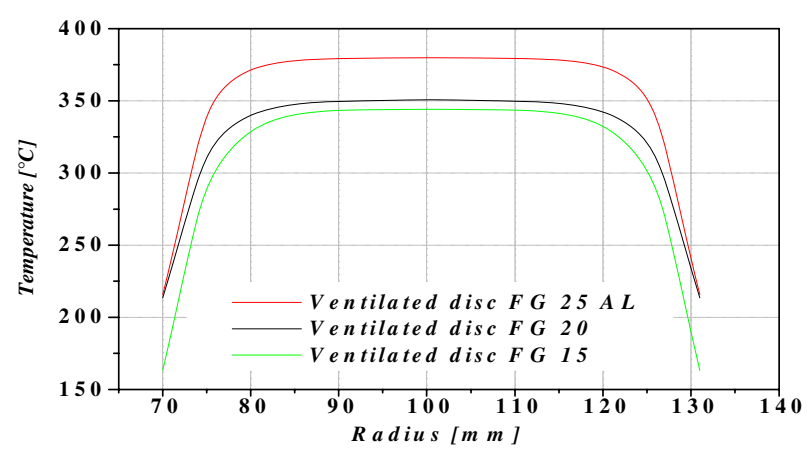

Fig. 23. Temperature variation through a radius for three types of cast irons (FG 25 AL, FG 20 and FG 15).

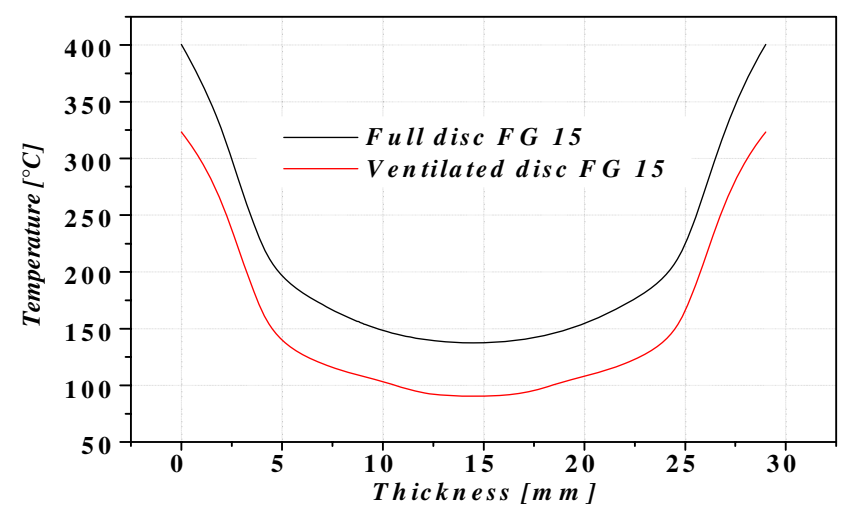

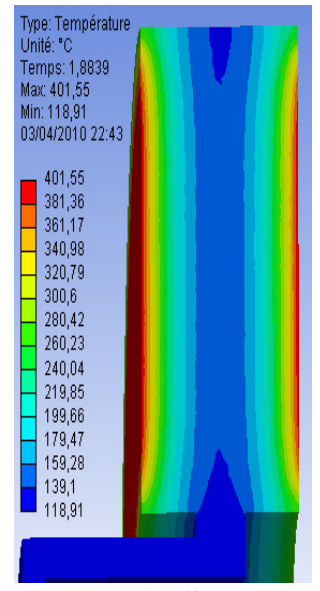

Full disc

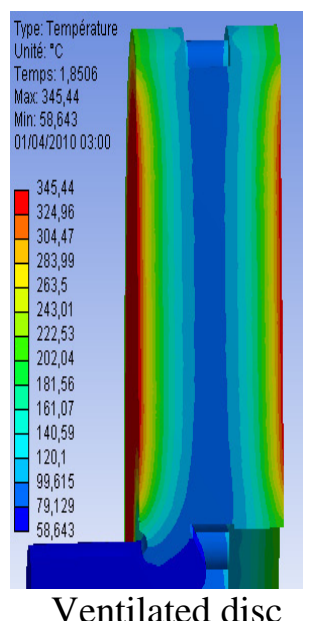

Ventilated disc
Fig. 24. Temperature variation through the thickness for both designs with same material (FG15).

The influence of ventilation on the temperature field appears clearly at the end of the braking $(t=3.5 \mathrm{~s})$. Among the parameters having an influence on the thermal behavior of the discs brake there is the braking mode which depends on the driver and the circulation conditions. Certain modes of braking can involve the destruction of the disc and consequently to cause serious accidents of circulation. A braking mode is represented in the form of braking cycles, which describe the variation of vehicle speed versus time $(v=f(t))$.

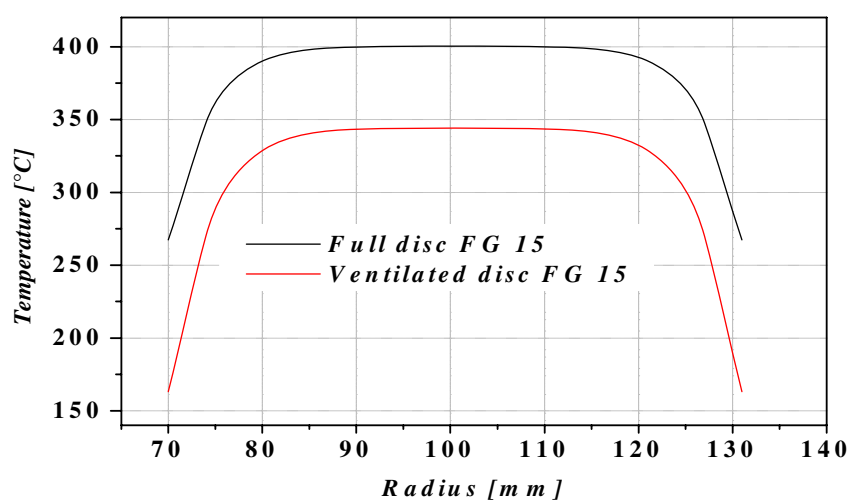

Fig. 25. Temperature variation through a radius or both designs with the same material (FG15).

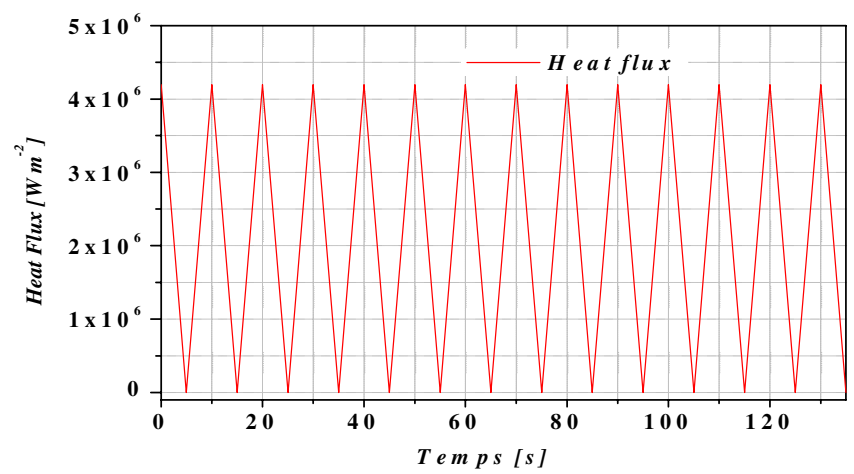

Fig. 26. Heat flux versus time in fading procedure.

These cycles may consist of a series of emergency brakings or cycles comprising of the braking phases followed by a downtime.

\subsection{Influence of braking mode}

The disc brake and the wheel are dimensioned according to the performance and economic requirements of the vehicle. They must support mechanical and thermal loads increasingly greater at mean velocities in permanent progression.

\subsubsection{Repeated braking}

During vehicle operating, the braking system is subjected to repeated actions of the driver. In this study, we considered two types of braking of which the total simulation time is estimated to be equal to $135 \mathrm{~s}$.

Figures 26 and 27 show the heat flux dissipated by friction and a driving cycle of fourteen successive brakings, in the form of saw tooth.

Figure 28 shows another mode of braking where after each phase of braking one has an idle.

Figure 29 shows the comparison of the change of temperature of the disc for a cyclic braking process between the first mode and the second mode. For two contours, we note that the temperatures in the disc rise firmly with 


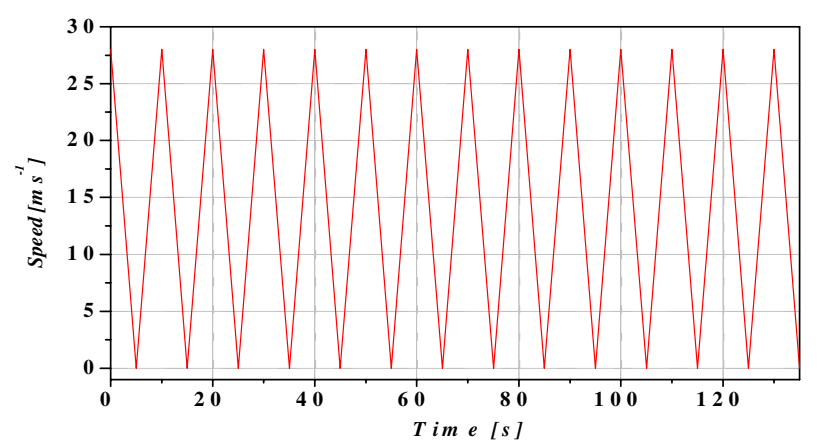

Fig. 27. Driving cycle with fourteen repeated braking (mode 1$)$.

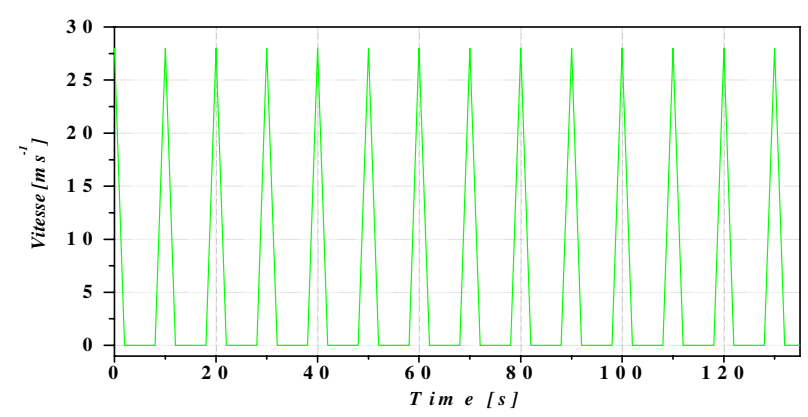

Fig. 28. Cycle braking with phase of idles after each braking (mode 2).

each application of brake, then begin the exponential decline. The more the number of repetitions of braking increases, the more the maximum temperatures increase. The initial state of the disc changes after each cycle, the downtimes allow only one partial cooling. After each cooling phase, the disc begins to warm again. In fact, during successive brakings the capacity of cooling of the disc is insufficient to lower the surface temperature to near the initial temperature, which causes an accumulation of energy and therefore a higher surface temperature. These results show that the transient thermal behavior of a disc brake depends on the braking cycle imposed and it is dominating because it dictates the cooling time of the disc. According to Figure 29, we note that in the case of braking cycle mode 2 , a reduction of the temperature of approximately $535{ }^{\circ} \mathrm{C}$ is $45.19 \%$ compared to the first cycle. We conclude that the braking mode with a cooling phase influences very positively on the heat transfers in the disc what involves a reduction in the maximum temperature of interface which causes cracking and mechanical wear. In addition this tendency will enable us to ensure safety and fatigue life of the brake system component. Finally it would be interesting to carry out this calculation on brake test benches in order to validate these results of the numerical simulation.

\section{Conclusion}

In this study, we presented a numerical simulation of the thermal behavior of a full and ventilated disc in

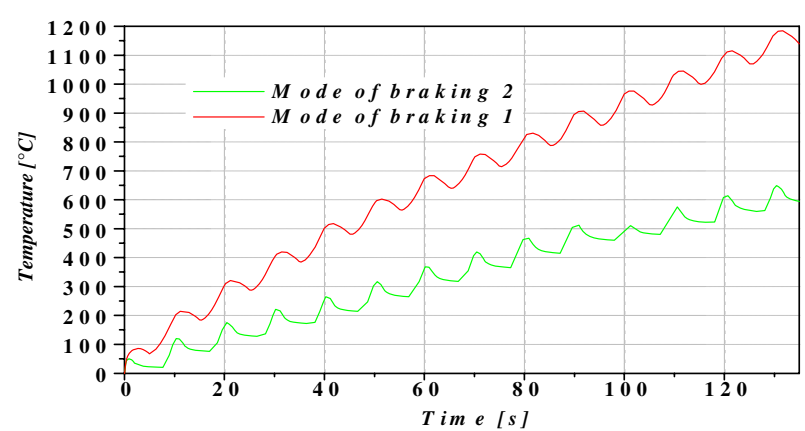

Fig. 29. Temperature variation of the two braking modes versus time.

transient state. By means the computer code ANSYS 11 we were able to study the thermal behavior of three types of cast iron (AL FG 25, FG 20, FG 15) for a determined braking mode. In addition to the influence of the ventilation of the disc, we also studied the influence of the braking mode on the thermal behavior of the discs brake. The numerical simulation shows that radial ventilation plays a very significant role in cooling of the disc in the braking phase. The obtained results are very useful for the study of the thermomechanical behavior of the disc brake (stress, deformations, efficiency and wear).

Through the numerical simulation, we could note that the quality of the results concerning the temperature field is influenced by several parameters such as:

- Technological parameters illustrated by the design.

- Numerical parameters represented by the number of elements and the step of time.

- Physical parameters expressed by the type of materials.

- Braking mode implemented.

Modeling of the disc material must take account of the anelastic behavior of the cast iron according to the real temperature of the disc. To be predictive, the calculation of the disc must respect the complexity of the system (three-dimensional problem, rotation of the disc, anelastic material behavior, and anisothermal stress...).

An experimental study of the thermomechanical behavior of the brake discs and brake pads is essential to validate the numerical results.

\section{References}

[1] H. Belghazi, M. El Ganaoui, J.C. Labbe, Analytical solution of unsteady heat conduction in a two-layered material in imperfect contact subjected to a moving heat source, Int. J. Thermal Sci. 49 (2010) 311-318

[2] T. Nakatsuji, K. Okubo, T. Fujii, M. Sasada, Y. Noguchi, Study on crack initiation at small holes of one-piece brake discs, Soc. Automot. Eng., Inc 2002-01-0926, 2002

[3] T. Valvano, K. Lee, An analytical method to predict thermal distortion of a brake rotor, Soc. Automot. Eng., Inc 2000-01-0445, 2000

[4] M.D. Hudson, R.L. Ruhl, Ventilated brake rotor air flow investigation, Soc. Automot. Eng., Inc 1997-01-033, 1997 
[5] J. Denape, N. Laraqi, Aspect thermique du frottement : mise en évidence expérimentale et éléments de modélisation, Mécanique \& Industries 1 (2000) 563-579

[6] M. Hamraoui, Thermal behaviour of rollers during the rolling process, Appl. Therm. Eng. 29 (2009) 2386-2390

[7] M. Hamraoui, Z. Zouaoui, Modelling of heat transfer between two rollers in dry friction, Int. J. Thermal Sci. 48 (2009) 1243-1246

[8] N. Laraqi, Velocity and relative contact size effect on the thermal constriction resistance in sliding solids, ASME J. Heat Transf. 119 (1997) 173-177

[9] H. Yapıcı, M.S. Genç, G. Özısık, Transient temperature and thermal stress distributions in a hollow disk subjected to a moving uniform heat source, J. Therm. stress. 31 (2008) 476-493

[10] A. Baïri, N. Alilat, J.G. Bauzin, N. Laraqi, Threedimensional stationary thermal behavior of a bearing ball, Int. J. Thermal Sci. 43 (2004) 561-568

[11] N. Laraqi, Thermal impedance and transient temperature due to a spot of heat on a half-space, Int. J. Thermal Sci. 49 (2010) 529-533

[12] A. Baïri, J.M. Garcia-de-Maria, N. Laraqi, Effect of thickness and thermal properties of film on the thermal behavior of moving rough interfaces, Eur. Phys. J. - Appl. Phys. 26 (2004) 29-34

[13] D. Majcherczak, P. Dufrénoy, M. Naït-Abdelaziz, Thermal simulation of a dry sliding contact using a multiscale model - application to the braking problem, Therm. Stress., Osaka (Japan), 2001, pp. 437-440

[14] F. Colin, A. Floquet, D. Play, Thermal contact Simulation in 2-D and 3-D mechanisms, ASME J. Tribol. 110 (1988) 247-252

[15] T.P. Newcomb, Transient temperatures attained in disk brakes, British J. Appl. Phys. 10 (1959) 339-340

[16] Fiche U.I.C. 541-3: FREIN - Frein à disques et garnitures de frein à disques, $4^{\mathrm{e}}$ édition, 1993

[17] E. Saumweber, Temperaturberechnung in bremsscheiben fürein beliebiges fahrprogramm, Leichtbau der Verkehrsfahrzeuge, Heft 3, 1969, Augsburg

[18] C. Cruceanu, Frâne pentru vehicule feroviare (Brakes for railway vehicles), edition Matrix Rom, Bucuresti, ISBN 978-973-755-200-6, 2007, p. 388
[19] J. Reimpel, Technologie de freinage, Vogel Verlag, Würzburg, 1998

[20] Gotowicki, Pier Francesco; Nigrelli, Vinzenco; Mariotti, Gabriele Virzi. Numerical and experimental analysis of a pegs- wing ventilated disk brake rotor, with pads and cylinders, 10th EAEC European Automotive Congress Paper EAEC05YUAS04- P 5, 2005

[21] VDI-Wearmeatlas4. Auflage, 1984

[22] S. Morgan, R.W. Dennis, A theoretical prediction of disc brake temperatures and a comparison with experimental data, Girling Ltd. England. SAE-Paper 720090

[23] W.M. Kays, I.S. Bjorklund, Heat transfer from a rotating cylinder with and without crossflow, Stanford University, ASME-Paper No. 55-a-71

[24] L.D. Dorfman, Hydrodynamic resistance and heat loss of rotating solids, Oliver and Boyd, 1963

[25] H.-R. Ehlers, Die mechanischen und waermetechnischen eigen selbstbeluefteten scheibenbremsen archiv fuer eisenbahntechnik, 1961

[26] L.D. Dorfman, Hydrodynamic resistance and heat loss of rotating solids, oliver and boyd, L963

[27] A. Fukano, H. Matsui, Development of a disc-brake design method using computer simulation of heat phenomena, SAE-Paper 860634

[28] H.W. Schwartz, L.L. Hartter, S.K. Rhee, J.-E. Byers, Evaluation of gray lron brake discs for trucks by thermal modeling, Bendix Corp. SAE - Paper 751013

[29] W.H. Mc. Adams, Heat Transmission. 3rd edition, Mc. Graw-Hill Book Co., inc. L954, p. 180

[30] G.P. Merker, Konvektive Waermeuebertragung, Springer-Verlag Berlin Heidelberg, 1987

[31] E.C. Chevereau Yves, Simulation de l'échauffement d'un disque de frein d'une moto de compétition sous Star-CD, Projet de formation Université de Maine

[32] ANSYS 11.0 User's Manual Guide

[33] H. Carlos, Galindo Lopez, Evaluating new ways of conducting convective heat dissipation experiments with ventilated brake discs, Cranfield University, Bedfordshire, MK43 OAL 